\title{
Larvicidal activity of metabolites from the endophytic Podospora sp. against the malaria vector Anopheles gambiae
}

\author{
Josphat C. Matasyoh • Birger Dittrich • \\ Anja Schueffler $\cdot$ Hartmut Laatsch
}

Received: 9 September 2010 / Accepted: 16 September 2010/Published online: 5 October 2010

(C) The Author(s) 2010. This article is published with open access at Springerlink.com

\begin{abstract}
In a screening for natural products with mosquito larvicidal activities, the endophytic fungus Podospora sp. isolated from the plant Laggera alata (Asteraceae) was conspicuous. Two xanthones, sterigmatocystin (1) and secosterigmatocystin (2), and an anthraquinone derivative (3) 13-hydroxyversicolorin B were isolated after fermentation on $\mathrm{M}_{2}$ medium. These compounds were characterised using spectroscopic and X-ray analysis and examined against third instar larvae of Anopheles gambiae. The results demonstrated that compound $\mathbf{1}$ was the most potent one with $\mathrm{LC}_{50}$ and $\mathrm{LC}_{90}$ values of 13.3 and $73.5 \mathrm{ppm}$, respectively. Over $95 \%$ mortality was observed at a concentration $100 \mathrm{ppm}$ after $24 \mathrm{~h}$. These results compared farvourably with the commercial larvicide pylarvex ${ }^{\circledR}$ that showed $100 \%$ mortality at the same concentration. Compound 3 was less potent and had an $\mathrm{LC}_{50}$ of $294.5 \mathrm{ppm}$ and over $95 \%$ mortality was achieved at a concentration of
\end{abstract}

J. C. Matasyoh $(\bowtie)$

Department of Chemistry, Egerton University,

P. O. Box 536, Egerton, Kenya

e-mail: josphat2001@yahoo.com

J. C. Matasyoh $\cdot$ H. Laatsch

Institute of Organic and Biomolecular Chemistry,

University of Göttingen,

Tammannstrasse 2,

37077 Göttingen, Germany

B. Dittrich

Institute of Inorganic Chemistry, University of Göttingen,

Tammannstrasse 4,

37077 Göttingen, Germany

\section{A. Schueffler}

Institute for Biotechnology and Drug Research,

Erwin-Schrödinger-Str. 56,

67663 Kaiserslautern, Germany
$1,000 \mathrm{ppm}$. Secosterigmatocystin (2) revealed relatively weak activity and therefore LC values were not determined.

\section{Introduction}

Mosquitoes are the major vector for the transmission of malaria, dengue fever, yellow fever, filariasis and several other diseases (James 1992). Mosquitoes also cause allergic responses on humans that include skin and systemic reactions such as angioedema (Peng et al. 1999). Most of the widely used vector interruption methods are synthetic insecticide-based. However, they not only affect the nontarget population but can also constantly increase mosquito resistance to the insecticide (Wattal et al. 1981). Therefore, the development of techniques that would provide more efficient insect control, do not have any negative effects on the non-target population, and are easily biodegradable is important (Redwane et al. 2002).

Fungal endophytes normally colonise living internal tissues of plants without causing any obvious negative effects or external symptoms. They may offer significant benefit to their host plants by producing secondary metabolites that provide protection and survival advantages to the plants, for example by providing plant growth regulators, antimicrobials, antivirals and insecticides or even mediating resistance to some types of abiotic stress (Stone et al. 2004). As less investigated microorganisms hidden within host plants, endophytes are a rich and reliable source of potentially bioactive metabolites with huge medical, agricultural and industrial potentials (Tan and Zou 2001).

We describe here the isolation and larvicidal activity of two xanthones, sterigmatocystin (1), secosterigmatocystin (2), and the anthraquinone derivative 13-hydroxyversicolorin B (3) from the culture broth of the endophytic Podospora sp. 
isolate LAF33. Compound $\mathbf{1}$ has been reported to be a potent inducer of topoisomerase II-mediated DNA cleavage indicating that it is also a potential antitumor agent (Asai et al. 1999).

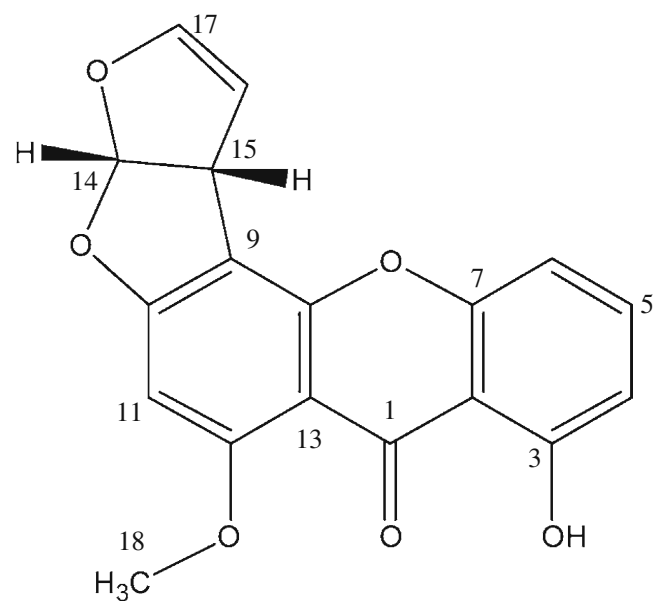

Sterigmatocystin (1)

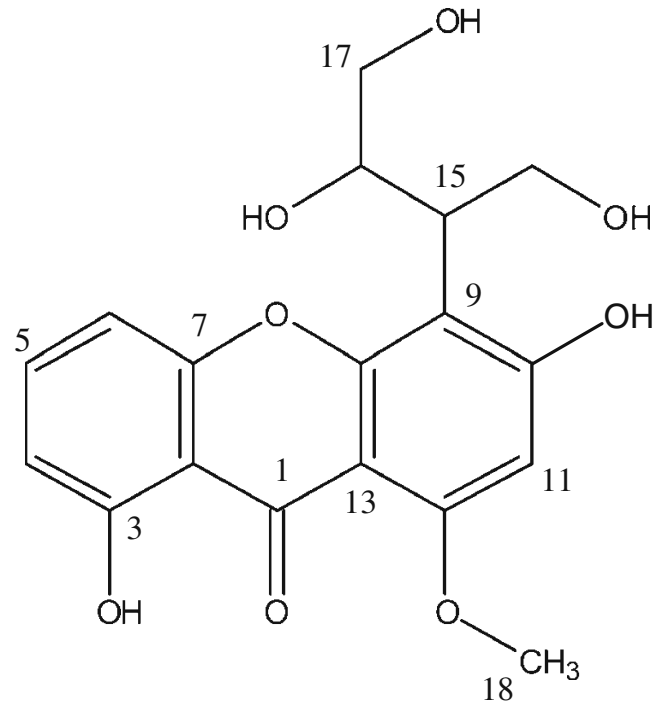

Secosterigmatocystin (2)

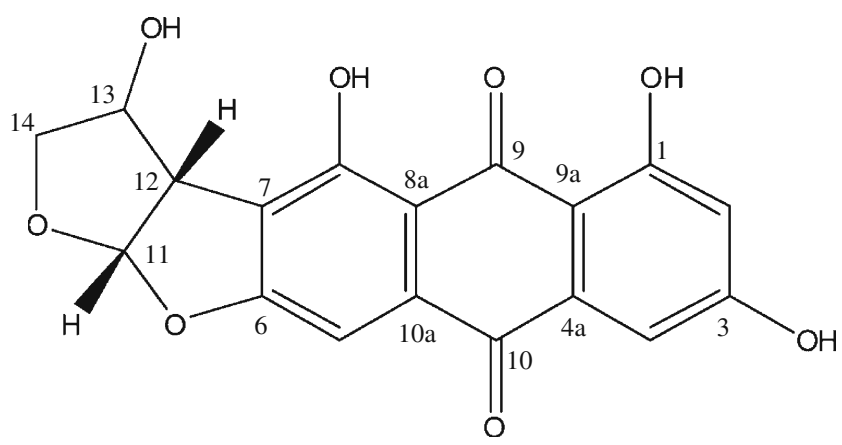

13-Hydroxyversicolorin B (3)

\section{Methods}

Fungal material

The Podospora sp. was isolated from the Kenyan medicinal plant Laggera alata (Asteraceae) collected from the edges of the Mau forest in the Rift Valley Province. The fungal isolate did not possess any morphological features in Petri dish culture and was therefore identified by internal transcribed spacer (ITS) sequencing. The ITS sequence shows homologies to different Podospora anserina species found in the GenBank database. To $P$. anserina ATCC MYA-4625 (GenBank Accession Nr. GU327641) and ATCC MYA-4624 (GenBank Accession Nr. GU327640), the homology is $99.6 \%$. To several other $P$. anserina species, the homology ranges between $96.6 \%$ and $99.6 \%$ (GenBank Accession Nrs. GQ922514-GQ922518). Although the genus Podospora is well known for growing on dung of herbivorous animals (Maheshwari 2005) representatives of this genus were isolated as endophytes from trees (Petrini and Fisher 1990), grass (Marquéz et al. 2007) as well as herbaceous plants (Caretta et al. 1999) and soil (Stchigel et al. 2002).

A culture of this fungus has been deposited at the Institute of Organic and Biomolecular Chemistry, University of Göttingen, Germany.

\section{Fermentation and isolation}

The endophytic Podospora sp. was cultivated in 20 of 1-L Erlenmeyer flasks each containing $250 \mathrm{mLM}_{2}$-medium ( $5 \mathrm{~g}$ malt extract, $2 \mathrm{~g}$ yeast extract and $2 \mathrm{~g}$ glucose per litre tap water, adjusted to $\mathrm{pH} 78$ and autoclaved at $129^{\circ} \mathrm{C}$ for $20 \mathrm{~min}$ ). The flasks were inoculated with approximately $1 \times$ $1 \mathrm{~cm}$ pieces of a 4-day-old culture of the fungus on $\mathrm{M}_{2}$ agar kept at $28{ }^{\circ} \mathrm{C}$ and sealed with pieces of cloth to permit aerobic growth. After incubation for 4 days on a linear shaker at $28^{\circ} \mathrm{C}$ and $95 \mathrm{rpm}$, the culture broth $(5 \mathrm{~L})$ was used to inoculate a Braun Biostat $\mathrm{U}$ fermentor (Braun, Melsungen, Germany) containing $20 \mathrm{~L}$ of $\mathrm{M}_{2}$ medium. The fermentation was done at the following conditions: stirring rate $200 \mathrm{rpm}, 28{ }^{\circ} \mathrm{C}, \mathrm{pH}$ regulation $6.5 \pm 1.5$, aeration $1.5 \mathrm{~m}^{3} / \mathrm{h}$. The culture was filtered through Celite to obtain the aqueous filtrate and mycelium. The latter was extracted exhaustively with EtOAc (extract $E_{\mathrm{A}}$ ) and $\mathrm{MeOH}$ (extract $\mathrm{E}_{\mathrm{B}}$ ). The aqueous filtrate was passed through an Amberlite XAD-16 column $(8 \times 120 \mathrm{~cm})$ and the adsorbed material eluted with $\mathrm{MeOH}$ (extract $\mathrm{E}_{\mathrm{C}}$ ). The solvents were removed by vacuum rotary evaporation to afford a brown extract in each case.

The EtOAc fraction $\mathrm{E}_{\mathrm{A}}$ was separated by column chromatography on silica gel with $\mathrm{MeOH}-\mathrm{CH}_{2} \mathrm{Cl}_{2}$ (1:9) to yield five major fractions $1-5$ according to their TLC 


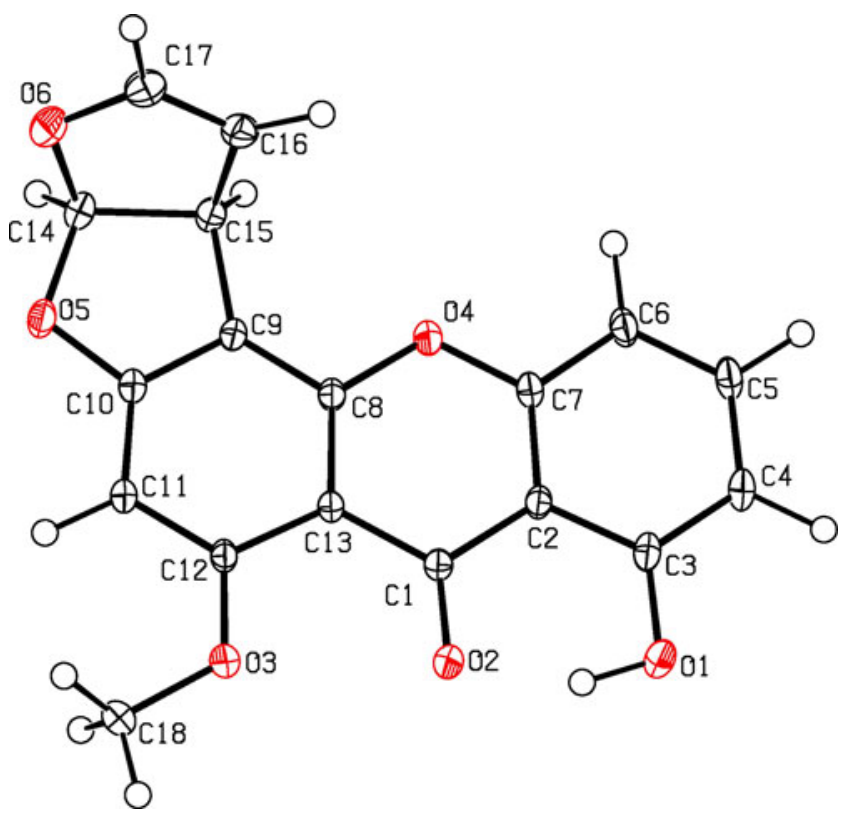

Fig. 1 X-ray structure of sterigmatocystin (1) (Deposited Data-CCDC 780811)

patterns. Fraction 3 was subjected to Sephadex LH-20 using $\mathrm{MeOH}$ to give two subfractions, which were further purified by preparative TLC with $\mathrm{MeOH}-\mathrm{CH}_{2} \mathrm{Cl}_{2}$ (1:9) to yield sterigmatocystin $\left(1, R_{\mathrm{f}}=0.78, \mathrm{CH}_{2} \mathrm{Cl}_{2} / 5 \% \mathrm{MeOH}\right.$; $15 \mathrm{mg})$ and 13-hydroxyversicolorin $\mathrm{B}\left(3, R_{\mathrm{f}}=0.51, \mathrm{CH}_{2} \mathrm{Cl}_{2} /\right.$ $5 \% \mathrm{MeOH} ; 13 \mathrm{mg})$. The $\mathrm{MeOH}$ eluent $\mathrm{E}_{\mathrm{B}}$ was concentrated under reduced pressure. The residue was fractionated on Sephadex LH-20 (MeOH) to yield from the first fraction by preparative TLC $10 \mathrm{mg}$ of secosterigmatocystin $\left(2, R_{\mathrm{f}}=0.67\right.$, $\mathrm{CH}_{2} \mathrm{Cl}_{2} / 5 \% \mathrm{MeOH}$ ).

Larvicidal assays

The compounds were dissolved in dimethylsulphoxide (DMSO, analytical grade, Lobarchemi) and diluted to the required concentration with spring water. The concentration of DMSO was kept below 1\%. The bioassay experiments were conducted according to standard WHO procedure (1981) with slight modifications. The bioassays were conducted at the Kenya Medical Research Institute, Centre for Disease Control (CDC), Kisumu, Kenya, where the insects were reared in plastic and enamel trays in spring river water. They were maintained and all experiments were carried out at $26 \pm 3{ }^{\circ} \mathrm{C}$ at humidity between $70 \%$ and $75 \%$. The bioassays were performed with third instar larvae of Anopheles gambiae and carried out in triplicate using 20 larvae for each replicate assay. The replicates were run simultaneously yielding a total of 60 larvae for each dosage. The larvae were placed in 50-ml disposable plastic cups containing $15 \mathrm{ml}$ of test solution and fed on tetramin fish feed (TetraMin ${ }^{\circledR}$ ) during all testing. Mortality and survival was established after $24 \mathrm{~h}$ of exposure. Larvae were considered dead if they were unrousable within a period of time, even when gently prodded. The number of the
Table $1{ }^{1} \mathrm{H}(300 \mathrm{MHz})$ and ${ }^{13} \mathrm{C}$ NMR data (125 MHz) of 13hydroxyversicolorin B (3) in DMSO- $d_{6}$

\begin{tabular}{|c|c|c|c|c|}
\hline Position & $\delta \mathrm{c}$ & $\delta_{\mathrm{H}}$ & $\mathrm{H}-\mathrm{H}$ COSY & HMBC \\
\hline 1 & 164.1 & & & \\
\hline 2 & 107.8 & $6.51(\mathrm{H}, \mathrm{d}, 2.4)$ & 4 & $1,3,4,9 \mathrm{a}$ \\
\hline 3 & 165.4 & & & \\
\hline 4 & 109.0 & $7.03(\mathrm{H}, \mathrm{d}, 2.4)$ & 2 & 4,10 \\
\hline $4 a$ & 134.4 & & & \\
\hline 5 & 101.2 & $6.98(\mathrm{H}, \mathrm{s})$ & & $7,8,8 \mathrm{a}, 10$ \\
\hline 6 & 159.1 & & & \\
\hline 7 & 117.1 & & & \\
\hline 8 & 165.0 & & & \\
\hline $8 \mathrm{a}$ & 110.5 & & & \\
\hline 9 & 188.4 & & & \\
\hline $9 \mathrm{a}$ & 108.0 & & & \\
\hline 10 & 180.4 & & & \\
\hline $10 \mathrm{a}$ & 135.2 & & & \\
\hline 11 & 112.8 & $6.60(\mathrm{H}, \mathrm{d}, 5.5)$ & 12 & $7,8,12,13,14$ \\
\hline 12 & 53.2 & $3.91(\mathrm{~d}, 5.5)$ & 11 & $6,7,8,11,13,14$ \\
\hline 13 & 72.7 & $4.44(\mathrm{~d}, 1.8)$ & 14 & $7,11,14$ \\
\hline 14 & 74.8 & $3.59(\mathrm{H}, \mathrm{dd}, 2.3,10.1), 3.91(\mathrm{H}, \mathrm{d}, 10.1)$ & 13 & $11,12,13$ \\
\hline
\end{tabular}


Table 2 Larvicidal activity of sterigmatocystin (1) against $A$. gambiae

${ }^{\mathrm{a}}$ Positive control
${ }^{\mathrm{b}}$ Negative control
${ }^{\mathrm{c}}$ Lethal concentrations with the
corresponding $95 \%$ confidence
intervals are shown in parenthesis

dead larvae in the three replicates was expressed as the percentage mortality for each concentration. The negative control was $1 \%$ DMSO in spring river water while the positive control was the pyrethrum-based larvicide pylarvex ${ }^{\circledR}$ (Pyrethrum Board of Kenya, PBK).

Statistical analysis

Probit analysis (Finney 1971) of concentration-dependent mortality data was conducted to estimate the $\mathrm{LC}_{50}$ and $\mathrm{LC}_{90}$ values with the statistical package SPSS.

\section{Results and discussion}

For compound 1, a molecular formula $\mathrm{C}_{18} \mathrm{H}_{12} \mathrm{O}_{6}$ was deduced from the positive high resolution electron spray ionization mass spectra (HRESIMS) pseudo-molecular ion peak at $\mathrm{m} / \mathrm{z} 347.05254$ (347.05261 calculated for $\left.\left[\mathrm{C}_{18} \mathrm{H}_{12} \mathrm{O}_{6} \mathrm{Na}\right]^{+}\right)$. Comparison of the ${ }^{1} \mathrm{H}$ and ${ }^{13} \mathrm{C}$ NMR data with those in the literature ( $\mathrm{Zhu}$ and Lin 2007) indicated sterigmatocystin. Crystallisation from methanol and X-ray crystallography confirmed the identity (see Fig. 1). Sterigmatocystin (1) is a typical metabolite of Aspergillus sp. and was previously described from Aspergillus multicolor (Cole and Cox 1981).
The molecular formula of compound $\mathbf{2}$ was established by HRESIMS of the pseudo-molecular ion peak at $\mathrm{m} / \mathrm{z}$ 385.08932 (calculated 385.08939 for $\left[\mathrm{C}_{18} \mathrm{H}_{18} \mathrm{O}_{8} \mathrm{Na}\right]$ ) as $\mathrm{C}_{18} \mathrm{H}_{18} \mathrm{O}_{8}$. The NMR spectra of $\mathbf{2}$ were similar to those of 1 indicating a xanthone as well. By comparison with reference data, compound $\mathbf{2}$ was elucidated as secosterigmatocystin (Maes and Steyn 1984; Zhu and Lin 2007). Interestingly, the ${ }^{13} \mathrm{C}$ NMR signals of the aliphatic side chain of this molecule together with those of the adjacent aromatic carbon atoms exhibited coalescence phenomena at $300 \mathrm{MHz}$ : Their signals were very broad and of low intensity at $28{ }^{\circ} \mathrm{C}$, but the intensity increased dramatically when measured at $100{ }^{\circ} \mathrm{C}$ suggesting conformational changes.

13-Hydroxyversicolorin B (3) showed a yellowish orange colour on TLC, which turned reddish with $\mathrm{NaOH}$ solution indicating a peri-hydroxyquinone. ESIMS afforded the molecular formula $\mathrm{C}_{18} \mathrm{H}_{12} \mathrm{O}_{8}$ by high resolution of the pseudo-molecular ion peak at $\mathrm{m} / \mathrm{z} 355.04583$ (calculated 355.04594 for $[\mathrm{M}-\mathrm{H}]^{-}$). By ${ }^{1} \mathrm{H}$ and ${ }^{13} \mathrm{C}$ NMR analysis, 3 was identified as a hydroxy derivative of versicolorin $\mathrm{B}$, which had been isolated previously from an Aspergillus species (Asai et al. 1998). As the NMR data are not easily accessible, they will be listed below (Table 1).

To evaluate the mosquito larvicidal activities of these metabolites, third instar larvae of the malaria mosquito $A$. gambiae were used. Tables 2 and 3 summarise the
Table 3 Larvicidal activity of 13-hydroxyversicolorin B (3) against $A$. gambiae

${ }^{\mathrm{a}}$ Positive control
${ }^{\mathrm{b}}$ Negative control
${ }^{\mathrm{c}}$ Lethal concentrations with the
corresponding $95 \%$ confidence
intervals are shown in parentheses

\begin{tabular}{lccc}
\hline Concentration $(\mathrm{ppm})$ & $\%$ Mortality $\pm \mathrm{SD}$ & $\mathrm{LC}_{50}(\mathrm{ppm})^{\mathrm{c}}$ & $\mathrm{LC}_{90}(\mathrm{ppm})^{\mathrm{c}}$ \\
\hline 0 & $0.0 \pm 0.0$ & & \\
50 & $0.0 \pm 0.0$ & & \\
100 & $1.7 \pm 2.9$ & $294.5(226.7-376.6)$ & $719.9(534.6-1195.2)$ \\
250 & $58.3 \pm 16.1$ & & \\
500 & $66.7 \pm 12.6$ & & \\
1,000 & $96.7 \pm 5.8$ & & \\
Pylarvex $\left(100 \mathrm{ppm}^{\mathrm{a}}\right.$ & $100 \pm 0.0$ & & \\
Spring water+DMSO $^{\mathrm{b}}$ & $0.0 \pm 0.0$ & \\
\hline
\end{tabular}


percentage mortality, $\mathrm{LC}_{50}$ and $\mathrm{LC}_{90}$ values after $24 \mathrm{~h}$ for compounds $\mathbf{1}$ and $\mathbf{3}$. Compound $\mathbf{2}$ revealed weak or no activity at all in some of the replicates and therefore no LC values were determined. The most potent compound was sterigmatocystin (1) with $\mathrm{LC}_{50}$ and $\mathrm{LC}_{90}$ values of 13.3 and $73.5 \mathrm{ppm}$, respectively. Experimental observation indicated that most of the larvae died within the first few hours. The high larvicidal activity of this compound was indicated by the fact that over $95 \%$ mortality was observed at a concentration of $100 \mathrm{ppm}$ after $24 \mathrm{~h}$, which compared favourably with the commercial larvicide pylarvex ${ }^{\circledR}$ used as standard.

13-Hydroxyversicolorin $\mathrm{B}(3)$ was less potent with $\mathrm{LC}_{50}$ and $\mathrm{LC}_{90}$ values of 294.5 and $719.9 \mathrm{ppm}$, respectively. A percentage mortality of 96.7 was observed at a concentration of $1,000 \mathrm{ppm}$. In comparisons of these LC values, sterigmatocystin (1) showed an excellent toxicity against the larvae of A. gambiae. Larvicidal activity of $\mathbf{1}$ and $\mathbf{2}$ was proportional to the dosage indicating a dose-dependent effect on mortality. As adult mosquitoes transmit diseases, the critical concentrations of the compounds that inhibit $50 \%$ $\left(\mathrm{LC}_{50}\right)$ of the treated larval population from emerging adults are more meaningful. There are few reported studies of the larvicidal activity of pure compounds on A. gambiae. A himachalene sesquiterpenoid isolated from Hugonia busseana showed moderate activity against this mosquito after $24 \mathrm{~h}$ at a concentration of $237 \mathrm{ppm}$ (Baraza et al. 2007). Azadirachtin which is commonly used as an insecticide and isolated from the plant Azadirachta indica showed an $\mathrm{LC}_{50}$ of $57.1 \mathrm{ppm}$ (Ndung'u et al. 2004) indicating less potency than compound 1. Two triterpenoids and nimocinol also isolated from $A$. indica showed $\mathrm{LC}_{50}$ values of 21,83 and 100 ppm against Aedes aegypti (Siddiqui et al. 2000), which compares well with those of $\mathbf{1}$. Gluanol acetate isolated from Ficus racemosa (Moraceae) is reported (Rahuman et al. 2008) to have shown a high potency against fourth instar larvae of Anopheles stephensi with $\mathrm{LC}_{50}$ and $\mathrm{LC}_{90}$ values of 28.50 and $106.50 \mathrm{ppm}$, respectively. The methanol extract of the seeds of Clitoria ternatea (Fabaceae) also showed a high mosquito larvicidal activity against the larvae of $A$. stephens $i$ with an $\mathrm{LC}_{50}$ value of $65.2 \mathrm{ppm}$ (Mathew et al. 2008). In general, Sterigmatocystin (1) had a better efficacy when compared with the examples indicated here.

\section{Conclusions}

Results of this study suggest that compounds $\mathbf{1}$ and $\mathbf{3}$ are potential natural mosquito larvicides. Moreover, these findings could be useful in the search for more selective, biodegradable and natural larvicidal compounds or can be used as leads for the development of environmentally friendly larvicides. It should be stated that the known toxicity of 1 needs to be considered for this application.
Acknowledgements The authors would like to thank F. Lissy, R. Chepkorir and R. Amito for technical assistance, the Centre for Disease Control laboratories at the Kenya Medical Research Institute in Kisumu (Kenya) for availing their facilities for mosquito larvicidal tests and the Alexander von Humboldt Foundation (Germany) for financial support to JCM.

Open Access This article is distributed under the terms of the Creative Commons Attribution Noncommercial License which permits any noncommercial use, distribution, and reproduction in any medium, provided the original author(s) and source are credited.

\section{References}

Asai A, Yamashita Y, Ando K, Kakita S, Kita K, Suzuki Y, Mihara A, Ashizawa T, Mizukami T, Nakano H (1998) Compounds UCT1072-Patent EP0819684

Asai A, Yamashita Y, Ando K, Kakita S, Kita K, Suzuki Y, Mihara A, Ashizawa T, Mizukami T, Nakano H (1999) UCT1072s, new antitumour antibiotics with topoisomerase II mediated DNA cleavage activity, from Aspergillus sp. J Antibiot 52:1046-1049

Baraza LD, Joseph CC, Nkunya MHH (2007) A new cytotoxic and larvicidal himachalenoid, rosanoids and other constituents of Hugonia busseana. Nat Prod Res 21:1027-1031

Caretta G, Piontelli E, Picco AM, Del Frate G (1999) Some filamentous fungi on grassland vegetation from Kenya. Mycopathologia 145:155-169

Cole RJ, Cox RH (1981) Handbook of toxic fungal metabolites. Academic Press Inc, London, pp 68-72

Finney DJ (1971) Probit analysis, 3rd edn. Cambride University Press, London

James AA (1992) Mosquito molecular genetics: the hands that feed bite back. Science 257:37-38

Maes CM, Steyn PS (1984) Polyketide-derived fungal metabolites from Bipolaris sorokiniana and their significance in the biosynthesis of sterigmatocystin and aflatoxin $B_{1}$. J Chem Soc Perkin Trans 1:1137-1140

Maheshwari R (2005) Fungal biology in the 21st century. Curr Sci 88:1406-1418

Marquéz SS, Bills GF, Zabalgogeazcoa I (2007) The endophytic mycobiota of the grass Dactylis glomerata. Fungal Diversity 27:171-195

Mathew N, Anitha MG, Bala TSL, Sivakumar SM, Narmadha R, Kalyanasundaram M (2008) Larvicidal activity of Saraca indica, Nyctanthes arbor-tristis, and Clitoria ternatea extracts against three mosquito species. Parasitol Res 104:1017-1025

Ndung'u MW, Kaoneka B, Hassanali A, Lwande W, Hooper AM, Tayman F, Zerbe O, Torto B (2004) New mosquito larvicidal tetranortriterpenoids from Turraea wakefieldii and Turraea floribunda. J Agric Food Chem 52:5027-5031

Peng Z, Yang J, Wang H, Simons FER (1999) Production and characterization of monoclonal antibodies to two new mosquito Aedes aegypti salivary proteins. Insect Biochem Mol Biol 29:909-914

Petrini O, Fisher PJ (1990) Occurrence of fungal endophytes in twigs of Salix fragilis and Quercus robur. Mycol Res 94:1077-1080

Rahuman AA, Venkatesan P, Geetha K, Gopalakrishnan G, Bagavan A, Kamaraj C (2008) Mosquito larvicidal activity of gluanol acetate, a tetracyclic triterpenes derived from Ficus racemosa Linn. Parasitol Res 102:333-339

Redwane A, Lazrek HB, Bouallam S, Markouk M, Amarouch H, Jana M (2002) Larvicidal activity of extracts from Querus Lusitania var infectoria gals (oliv). J Ethno Pharmacol 79:261-263 
Siddiqui BS, Afshan F, Ghiasuddin FS, Naqvi SN, Tariq RM (2000) Two insectcidal tetranortriterpenoids from Azadirachta indica. Phytochemistry 53:371

Stchigel AM, Calduch M, Guarro J, Zaror L (2002) A new species of Podospora from soil in Chile. Mycologia 94:554-558

Stone JK, Polishook JD, White JF (2004) Endophytic fungi. In: Mueller GM, Bills GF, Foster MS (eds) Biodiversity of fungi: inventory and monitoring methods. Elsevier Academic Press, China, pp 241-270
Tan RX, Zou WX (2001) Endophytes: a rich source of functional metabolites. Nat Prod Rep 18:448-459

Wattal BL, Joshi GC, Das M (1981) Role of agricultural insecticides in precipitating vector resistance. J Comm Dis 13:71-73

WHO (1981) Instructions for determining susceptibility or resistance of mosquito larvae to insecticides. WHO/VBC-81, pp 807

Zhu F, Lin Y (2007) Three xanthones from a marine-derived mangrove endophytic fungus. Chem Nat Compd 43:132-135 